\title{
LA ESCUELA MODERNA Y SUS VÍNCULOS CON LOS CONCEPTOS ÁCRATAS
}

\author{
A escola moderna e seus vínculos com os conceitos ácratas
}

\section{The modern school and its connexions with the anarchist concepts}

\author{
Miriam Hermi Zaar \\ Departamento de Geografía da Universidad de Barcelona \\ Coordenadora do Portal Geocrítica, Universidad de Barcelona \\ miriamzaar@gmail.com
}

Artigo enviado para publicação em 09/11/2019 e aceito em 28/11/2019

DOI: $10.12957 /$ tamoios.2019.46556

\section{Resumen}

La creación de la Escuela Moderna (1901) fue un dos primeros intentos de establecer una educación racionalista y libertaria que contribuyese al desarrollo de una sociedad más igualitaria y justa. Para ello, Francisco Ferrer Guardia, basado en los ideales ácratas de Jean-Jacques Rousseau, Paul Robin y otros pedagogos desarrolló una metodología de enseñanza laica centrada en la coeducación, en la libertad de pensamiento y en las ciencias experimentales, a la que denominó 'Escuela Moderna'. Su propósito de instituir una escuela integral enfocada en el cientificismo positivista evolucionista, suscitó la enemistad y la persecución de la iglesia católica y de sectores civiles conservadores, que tuvo como consecuencia el cierre de su escuela, su encarcelamiento y fusilamiento en 1909.

Palabras clave: Educación racionalista y libertaria; pensadores ácratas; Francisco Ferrer Guardia; escuela laica integral.

\section{Resumo}

A criação da Escola Moderna (1901) foi uma das duas primeiras tentativas de estabelecer uma educação racionalista e libertária que contribuísse ao desenvolvimento de uma sociedade mais igualitária e justa. Francisco Ferrer Guardia, baseado nos ideais ácratas de Jean-Jacques Rousseau, Paul Robin e outros pedagogos, desenvolveu uma metodologia de ensino secular focada na coeducação, liberdade de pensamento e ciências experimentais, que ele chamou de 'Escola Moderno'. Seu propósito de instituir uma escola integral, focada no cientificismo evolutivo positivista, provocou a inimizade e a perseguição da igreja católica e de setores civis conservadores, o que resultou no fechamento de sua escola, na sua prisão e na sua execução em 1909.

Palavras-chave: Educação racionalista e libertária; pensadores ácratas; Francisco Ferrer Guardia; escola laica integral.

\begin{abstract}
The creation of the Modern School (1901) was one of the first attempts to establish a rationalist and libertarian education that would contribute to the development of a more egalitarian and just society. For this, Francisco Ferrer Guardia, based on the ideals of Jean-Jacques Rousseau, Paul Robin and others educators developed a method of lay teaching methodology, focused on co-education, on the liberation of thought and experimental science, which he called Escuela Modern'. His purpose of instituting a comprehensive school focused on positivist evolutionary scientism, led to enmity and persecution of the Catholic Church and conservative civil sectors, that resulted in the closure of its school, his imprisonment and execution in 1909.
\end{abstract}

Key words: Rationalist and libertarian education; anarchist thinkers; Francisco Ferrer Guardia; integral lay school. 


\section{Introducción}

El Renacimiento y la Ilustración fueron amplios movimientos culturales que se produjeron en Europa Occidental entre los siglos XV y XVIII y que se caracterizaron por una creciente valoración de la racionalidad, la ciencia y la naturaleza, y un progresivo debilitamiento de la influencia del dogmatismo religioso y del misticismo que prevalecieron sobre la cultura y la sociedad medievales.

El Renacimiento con sus enfoques renovados en las ciencias políticas, filosóficas, humanas, culturales, artísticas y naturales, substituyó el teocentrismo por el antropocentrismo. El ser humano fue revestido de una nueva dignidad y puesto en el centro del mundo, surgiendo la principal corriente de pensamiento en este período, el humanismo. Ésta posibilitó, entre otros procesos evolucionistas, que em siglo XVII los filósofos (considerados enemigos del cristianismo) debatiesen sus ideas en academias científicas, salones literarios, masonerías, cafés y en libros impresos y folletos.

A su vez, las ideas de la Ilustración, centradas en la razón como la principal fuente de autoridad y legitimidad, en los ideales democráticos de libertad, progreso, fraternidad y en la separación Iglesia-Estado, minaron la autoridad de la monarquía y de la Iglesia, cuestionando la legitimidad religiosa y preparando el camino para las revoluciones culturales y políticas de los siglos XVIII y XIX.

Los pensadores de la Ilustración creían que el conocimiento humano podría combatir la ignorancia, la superstición y la tiranía. Su principal contribución fue la defensa de métodos científicos para cualquier estudio o análisis.

Estos conceptos, estrechamente vinculados al racionalismo, corriente filosófica que se desarrolló en Europa durante los siglos XVII y XVIII, tuvieron una gran influencia en los movimientos sociales que surgieron durante el siglo XIX (socialismo, anarquismo y anarcosindicalismo). Creían que la educación podría desempeñar un papel esencial en el proceso de cambio del orden político y social vigente entonces (en aquella época).

Este texto se propone analizar la coyuntura cultural y política española y europea en la que se originó la Escuela Moderna, los pensadores que contribuyeron para su institución, así como reflexionar sobre los principios ácratas que la orientaron: una educación laica que protegiese los derechos de los niños, y que propiciase los medios para su desarrollo integral, como ciudadano y como trabajador. Para esto, se estructura en cuatro partes. La primera trata de los planteamientos teóricos que contribuyeron a la creación de la Escuela Moderna y la segunda discurre sobre las primeras iniciativas vinculadas a la escuela racional y libertaria. A continuación, la tercera parte reflexiona sobre la trayectoria de Francisco Ferrer Guardia y la cuarta analiza el método y la praxis que caracterizan la Escuela Moderna.

El enfoque teórico que permea este original está vinculado a una revisión bibliográfica sobre los principales intelectuales de la Ilustración y los movimientos ácrata y pedagógico racionalistas del siglo XIX, cuyas ideas coadyubaron para la elaboración de un nuevo enfoque educacional. Asimismo, el texto contempla un análisis sobre el método y la praxis que abarca la Escuela Moderna y sus contribuciones a la educación racional y laica que se implantó a inicios del siglo XX.

\section{Los planteamientos teóricos que influyeron en la educación racionalista}

El desarrollo de conceptos racionalistas y libertarios (ácratas) fueron clave para la difusión de las ideas que marcaron el siglo XIX y la educación racionalista. Entre los teóricos destacan los franceses Jean-Jacques Rousseau, Pierre-Joseph Proudhon y Élisée Reclus y los rusos Mijail Bakunin y Piotr Kropotkin. 


\section{El filósofo y pedagogo Rousseau}

Jean-Jacques Rousseau (1712-1778), en su obra El Contrato Social (1762) afirma que "el hombre ha nacido libre, y en todas partes se halla entre cadenas". Resalta que renunciar a la libertad es renunciar a la calidad del ser humano, a los derechos de la humanidad y a sus mismos deberes, lo que es incompatible con su naturaleza.

En el aspecto pedagógico, Rousseau se centró en la evolución natural del niño. En su tratado filosófico sobre la naturaleza del ser humano (Emilio, o De la educación) ilustra como se debe educar al ciudadano ideal, motivo por el que, durante la Revolución Francesa, sirvió como inspiración al nuevo sistema educativo nacional.

\section{Pierre-Joseph Proudhon. Uno de los padres del pensamiento ácrata}

En concordancia con estos preceptos, el filósofo, político y revolucionario Pierre-Joseph Proudhon (1809-1865) fue el primer pensador que se definió como anarquista (del griego "anarkia" que se traduce por ausencia de jerarquía, de autoridad y de gobierno). Su gran contribución al anarquismo clásico está fundamentada en su enfoque, según el cual el capital y el Estado se mezclan y confunden de tal manera que inviabiliza la emancipación del proletariado por medio de este último. Como consecuencia defiendió una sociedad cooperativa, organizada a partir de un sistema federativo (mutualismo), capaz de garantizar el control democrático de la sociedad y de la economía, a través de la autogestión. La base del sistema proudhiano está asentada en la idea de justicia, equidad e igualdad (PROUDHON, 1975, p. 13; ZAAR, 2015, p. 16).

Para Proudhon el hombre más libre es el que tiene el máximo de relaciones con sus semejantes, lo que lleva a la realización de la personalidad del "ser colectivo" que se forma cuando hay interacción mutua. También fue Proudhon quien teorizó el concepto de "lucha de clases", retomado posteriormente y profundizado por los teóricos marxistas (PROUDHON, 1975; ZAAR, 2015, p. 16).

Fue con base en este marco teórico, que se construyeron las ideas anarquistas según las cuales el ser humano no nace bueno o malo, pero con potencialidades que desarrolla en uno u otro sentido, bajo la influencia del medio (social y natural) en que vive. Asimismo, la dialéctica de Proudhon estuvo ampliamente vinculada a los principios de ayuda mutua como motor de la humanidad.

\section{Mijail Bakunin, Elisée Reclus y Piotr Kropotkin}

Bakunin, Reclus y Kropotkin, los principales representantes del movimiento ácrata en la Europa de la segunda mitad del siglo XIX, recibieron una gran influencia de Roussseau y de Proudhon. Sus principales contribuciones en el campo de la educación estuvieron asociadas a la difusión de los principios sociales y educativos que desembocaron en la educación racionalista surgida a finales del siglo XIX.

\section{Mijail Bakunin}

El filósofo ruso Mijail Bakunin (1814-1876), al sostener que el hombre es producto del medio social en que vive, propuso que, para que los hombres fueran libres, hombres completos en el pleno sentido de la palabra, serían necesarias tres condiciones básicas: 
a) una educación racional e integral basada en el respeto al trabajo, la razón, la igualdad y la libertad;

b) un medio social donde cualquier individuo, aprovechando la plena libertad, sea igual de hecho y de derecho a todos los demás;

c) buenas condiciones de salud e higiene (BAKUNIN,1953).

También afirmó que "los obreros necesitan educación, ocio y conocimiento de los asuntos", y complementó "es imposible elevar el grado de autoconciencia sin ayuda educativa, de la ciencia y experiencia política" (BAKUNIN, 1953, p. 248-449).

Para Bakunin, sólo se puede conseguir el desarrollo íntegro del individuo y la plena realización de sus facultades y de su potencial humano a través de la educación, la instrucción científica y la prosperidad material (BAKUNIN, 2000-2001, p. 60). Sobre la educación integral afirmó:

\begin{abstract}
"La instrucción a todos los niveles debe ser igual para todos, por consiguiente, debe ser integral, o sea que debe preparar cada niño de ambos sexos tanto a la vida del pensamiento como a la del trabajo, afín de que todos puedan también convertirse en hombres completos" (BAKUNIN,1869).
\end{abstract}

Elisée Reclus

El francés Elisée Reclus (1830-1905), respaldado por las teorías que defienden la libertad, la justicia social, el progreso armónico con la naturaleza y la cooperación universal, fue el primer geógrafo que se preocupó de las cuestiones sociales, desarrollando una geografía social integradora, objetiva, compleja y comprometida, para analizar el mundo con toda su complejidad. Participó activamente en la Comuna de París, donde desarrolló actividades educativas para profesores, asociadas a la oferta de clases de geografía y de otros temas.

En su principal obra El Hombre y la Tierra, analizó, entre otras cuestiones, la ausencia de la libertad individual y la desigualdad económica y social como fuente del "retroceso", e inversamente, encontró en la libertad individual y en la igualdad económica y social, la fuente del progreso. Reconoció, por lo tanto, que es en la libertad donde está contenido el desarrollo social completo (RECLUS, 1985, p. 40).

En su único libro de teorización política La evolución, la revolución y el ideal anarquista (1897) afirmó que la emancipación de los trabajadores será obra de los propios trabajadores. Propuso como primera condición para esta emancipación liberarse de la ignorancia, ya que considera que los enemigos del pensamiento son, por lógica, los enemigos de toda libertad. Para Reclus, el ser humano necesita ser libre. Él debe pensar, hablar y actuar libremente. Son las condiciones indispensables de todo progreso (RECLUS, 2002, cap. 4 y $5)$.

\title{
Piotr Kropotkin
}

En cuanto al geógrafo ruso Piotr Kropotkin (1842-1921), éste planteó un modelo de sociedad cuyo bienestar colectivo comprendiera: el reparto igual de alimentos, vivienda para todos, trabajo digno con jornadas reducidas, oferta de servicios de calidad, etc., con el objetivo de recuperar la unidad de la vida social de las ciudades, sus condiciones "orgánicas". En pocas palabras "¡Pan, casa y bienestar para todos!". Este tema se convirtió en la esencia de su reflexión anarquista y repercutió en su modo de concebir la ciudad y el territorio (KROPOTKIN, 1973; ZAAR, 2016, p.10) 
Kropotkin también propuso que la base para esta nueva sociedad fuera la educación. Planteó una profunda modificación del sistema de educación de la época. En lugar de una educación técnica que mantiene la división del trabajo y la separación drástica entre el trabajo intelectual y el trabajo manual, transformando el trabajo humano en un apéndice de carne y hueso de una inmensa máquina, defendió la necesidad de una educación integral, amplia, filosófica y científica.

Esto posibilitaría la "integración de las capacidades" de todos los trabajadores, comprendiendo el ejercicio de actividades manuales e intelectuales en las direcciones que quisieran (KROPOTKIN, 1978, p. 7; ZAAR, 2016, p. 10-11).

Para estos pensadores, se trata de poner en marcha un proceso evolutivo en el que la educación aparezca como medio para alcanzar una finalidad: cambiar las conciencias para conseguir libertad e igualdad social. Así, a través de la educación, el ideal anarquista pretendía crear un nuevo hombre y con él una nueva sociedad fundada en la igualdad y en la justicia social.

\section{Educación racionalista. Primeras experiencias}

Aunque a nivel intelectual (teórico y filosófico), técnico-científico y cultural se habían producido nuevas formas de entender la sociedad y el mundo, a partir de una fuerte crítica al absolutismo político y la sumisión del ser humano a los regímenes autoritarios, gran parte de los sistemas educativos europeos del siglo XIX y del inicio del XX continuaban bajo el control de la Iglesia y atendían a un número limitado de la población.

En países católicos, como España, el papel de la Iglesia Católica en las decisiones y acciones educativas era notorio y cualquier intento de romper con esta sujeción, estuvo, durante mucho tiempo, condenado al fracaso. El monolitismo clerical siempre se imponía.

Entre las costumbres y prácticas educativas que se contradecían con las teorías progresistas desarrolladas a partir del siglo XV se encontraban, por ejemplo, la priorización de las instituciones educativas religiosas (educación confesional), ante las escuelas laicas, la utilización de métodos de memorización, la separación de alumnos por sexos, los castigos corporales, la falta de libertad, la obediencia ciega, etc.

Esto ocurría, a pesar del surgimiento del movimiento racionalista escolar, que dio lugar al nacimiento de la pedagogía científica.

Ésta, además de estar estrechamente relacionada con los ideales racionalistas de varios pensadores, muchos de ellos interesados en la educación popular, también estuvo muy asociada a numerosas experiencias en la educación básica (infantil y adulta) enfocadas en los principios de racionalidad, libertad y desarrollo integral del individuo, en las que tuvieron un papel esencial, entre otros, los educadores Enrique Pestalozzi y Paul Robin.

\section{El influyente pedagogo Enrique Pestalozzi}

Enrique Pestalozzi (1746-1827) recibió una gran influencia de Rousseau a través de su obra Emilio. Creía que las contradicciones y a la pobreza social deberían ser resueltas con una educación creativa y productiva, en la que se fomentase el dibujo y los juegos infantiles, con la finalidad de obtener un mayor desarrollo del niño. Defendía que no se debería proporcionarles conocimientos ya construidos, sino la oportunidad de aprender por sí mismos mediante la actividad personal, y que los profesores tendrían que estar preparados para lograr su desarrollo integral. En sus palabras: 


\begin{abstract}
"Debemos tener presente que el fin último de la educación no es la perfección en las tareas de la escuela, sino la preparación para la vida; no la adquisición de hábitos de obediencia ciega y de diligencia prescrita, sino una preparación para la acción independiente. Debemos tener en cuenta que cualquiera que sea la clase social a que un discípulo pueda pertenecer y cualquiera que sea su vocación, hay ciertas facultades en la naturaleza humana, que son comunes a todos y que constituyen el caudal de las energías fundamentales del hombre. No tenemos derecho a privar a nadie de las oportunidades para desenvolver todas estas facultades" (PESTALOZZI, 1827. Carta XXI, 14 de febrero de 1819).
\end{abstract}

Así, según Pestalozzi, "la educación en vez de considerar meramente lo que hay que proporcionar al niño, debe considerar primeramente lo que puede decirse que ya posee, si no como algo desarrollado, al menos como una facultad implicada capaz de desenvolverse" (PESTALOZZI, 1827. Carta XXI, 14 de febrero de 1819).

Pestalozzi aseguraba que la educación, más que implantar en los niños conocimiento, lo que constituye solamente parte de la educación, debería tener como objetivo formar un "hombre integral". Con el objetivo de desarrollar las capacidades humanas gradualmente, defendía la educación a partir de la observación de las experiencias y actividades educativas. Su lema era: "el aprendizaje por la cabeza, la mano y el corazón (UNESCO, 1999, p. 7).

Fundó varias instituciones educativas en Alemania y regiones de Suiza de lengua francesa y escribió obras como Mis Investigaciones (1797) que explican los principios revolucionarios de la educación. Su actividad contribuyó a la erradicación de gran parte del analfabetismo en la Suiza del siglo XVIII.

\title{
El pedagogo anarquista francés Paul Robin
}

Paul Robin (1837-1912), miembro activo de la Asociación Internacional de Trabajadores (AIT), compañero de Bakunin y participante en la Comuna de París, también fue un defensor de la educación integral.

Creía que el desarrollo adecuado de los niños pobres dependía de un medio social adecuado: amor, libertad y, sobre todo, atención a sus necesidades, lo que destruiría el estigma de haber nacido pobre. Sus prácticas educativas, basadas en las teorías proudhonianas sobre la educación integral, estimulaban toda clase de actividades físicas, manuales, intelectuales y educativas. También defendió el anti-autoritarismo, el internacionalismo pacifista y la emancipación femenina.

Robín rechazó todo intento de crear nociones fijas aprendidas de memoria como un catecismo. Propuso un método anti dogmático en el que la imposición, el deber y la religión deberían ser sustituidos por la ciencia porque "La ciencia y el trabajo unidos liberarían el mundo" (ROBIN, 1981, p. 32 [1906]).

Concibió una teoría de la educación basada en la concepción unitaria del conocimiento y en el repudio a la verdad no demostrable. Defendió la eliminación de los diplomas y títulos, instituyendo una escuela abierta, en la que el talento del educador sustituyese las obligaciones.

Definió la educación integral como aquella que contemple, la totalidad de las funciones humanas: sensibilidad, afectividad, raciocinio, esto es, sentidos e inteligencia. En sus palabras:

"La instrucción integral, recíprocamente fin y medio de educación, se define: como un conjunto completo, encadenado, sintético, paralelamente progresivo en todo orden de conocimientos, y todo ello a partir de la más joven edad y de los primeros elementos. En todas las grandes ramas del saber humano que más tarde fueron ramificándose hasta el infinito, están en origen, en la base, verdades 
simples, primordiales, y fundamentales, fácilmente observables e inteligibles, incluso para los niños: deben constituir el primer tesoro de nociones, poseído por el pequeño alumno, y destinado a enriquecerse gradualmente" (ROBIN, 1981, p. 47 [1906]).

Entre 1880 y 1894 Paul Robin puso en práctica en el Orfanato de Cempuis la teoría sobre educación integral que había formulado desde 1869 y1870. Esta educación, basada en la convicción de la igualdad de todos en el acceso a la educación, pretendía ofrecer a los niños de clases desfavorecidas una educación completa en la que se incluía la práctica de deportes, la música y el aprendizaje manual. Otro aspecto muy innovador de su trabajo fue la "coeducación de los sexos" educando a niños y niñas juntos.

\title{
España. Los avances del siglo XIX
}

A pesar de que, entre 1799 y 1832 se publicasen varias obras de filósofos franceses de carácter racionalista, y de que durante el siglo XIX hubiesen existido experiencias educativas de carácter integral puestas en práctica en sociedades, institutos y ateneos que se dedicaban a la enseñanza humanista y técnica, fue sólo en el período del Sexenio Democrático (1868-1874), con la creación de la sección madrileña de la Asociación Internacional del Trabajo que las mismas pasaron a tener protagonismo. Su primer congreso, celebrado en Barcelona en 1870, dedicó un capítulo a la educación y a la organización del proletariado "a su derecho a la enseñanza integral en todas las ramas del saber humano" (LIDA, 1971; SAFÓN, 1994).

Sin embargo, fue en su $2^{\circ}$ congreso (1872) que este proyecto se puso en práctica a través del siguiente ordenamiento pedagógico:

\begin{abstract}
"El alumno pasará por tres fases formativas: en la primera se educará artísticamente, desarrollando su sensibilidad. Luego emprenderá el estudio de las ciencias exactas, naturales y sociales, es decir, la parte intelectual propiamente dicha. Una vez completadas estas etapas, pasará a profundizar los conocimientos teóricos de la técnica industrial. Sólo al cabo de esta preparación integral tendrá libertad de escoger el oficio que más le plazca." (ORTS RAMOS, In SAFÓN, 1994).
\end{abstract}

Este programa de acción, se anticipó en casi un lustro al de la Institución Libre de Enseñanza (1876) y en casi treinta años al de la Escuela Moderna de Ferrer.

Según Ramon Safón, el hecho que permitió que se adoptara el ideario anarquista en el concepto sobre la educación integral, fue la constitución en Francia del Comité ProEnseñanza Anarquista en 1989 por Elisée Reclus, Louise Michel, J. Ardouin, Carlos Malato, L. Tolstoi, P. Kropotkin, J. Grave, entre otros, que compilaron varios textos con contenidos que combatían la educación autoritaria. Este programa tenía como objetivos una enseñanza:

“a) Integral, o sea, tender al desarrollo armónico de todo el individuo y proporcionar un conjunto completo, sintético y paralelamente progresivo en todo orden de conocimientos intelectuales, fisicos, manuales y profesionales, ejercitando en este sentido a los niños en sus primeros arios;

b) Racional, o sea, fundada en la razón y conforme a los principios de la ciencia actual, y no en la fe; en el desarrollo de la dignidad e independencia personal, y no en el de la piedad y obediencia: en la abolición de la ficción divina, causa eterna y absoluta de la servidumbre;

c) Mixta, o sea, favorecer la coeducación de los sexos en una comunión constante, fraternal de los niños y niñas. Esta coeducación, en vez de constituir un peligro, aleja del pensamiento del niño curiosidades malsanas, y se convierte en las sabias 
condiciones en que debe ser observada, en garantía de preservación y alta moralidad;

d) Libertaria, o sea consagrar, en una palabra, el sacrificio progresivo de la autoridad en provecho de la libertad, toda vez que el objetivo final de la educación es el de formar hombres libres que respeten y amen la libertad ajena." (ROSELL, 1940, p. 4-5).

Estos principios fueron ampliamente difundidos, y en España estimularon importantes proyectos, como los impulsados por:

a) La Institución Libre de Enseñanza, un proyecto pedagógico que se desarrolló en España entre 1876 y 1936 y fue integrado por importantes catedráticos madrileños. Defendían la libertad de enseñanza y se negaron a ajustar la entidad educacional a los dogmas oficiales en materia religiosa, política o moral, por lo que tuvieron que proseguir con su trabajo educativo al margen del Estado, creando un establecimiento educativo laico (ILE) que comenzó por la enseñanza universitaria y se extendió a la educación primaria y secundaria.

b) La creación de la Escuela Moderna por el catalán Francisco Ferrer Guardia (18591909), inspirada en las ideas de Jean-Jacques Rousseau y Paul Robin, además de otros racionalistas ácratas y que analizaremos a continuación.

\section{La trayectoria de Francisco Ferrer Guardia}

Ferrer Guardia (figura 1) nació el 10 de enero de 1859 en Alella, Cataluña, España, en una familia de campesinos muy católica y monárquica. A los 14 años cuando su familia le envió a Barcelona para trabajar, entró en contacto con los ideales republicanos en sus clases nocturnas. Como miembro del Partido Republicano Progresista, participó activamente en 1886 en un movimiento que pretendió proclamar la República y que fracasó, por lo que se refugió en París. En esta ciudad tradujo al español obras que consideraba importantes para luchar contra el clericalismo español y desempeñó las funciones de profesor de lengua española.

\section{Figura 1. Francisco Ferrer Guardia hacia 1909}

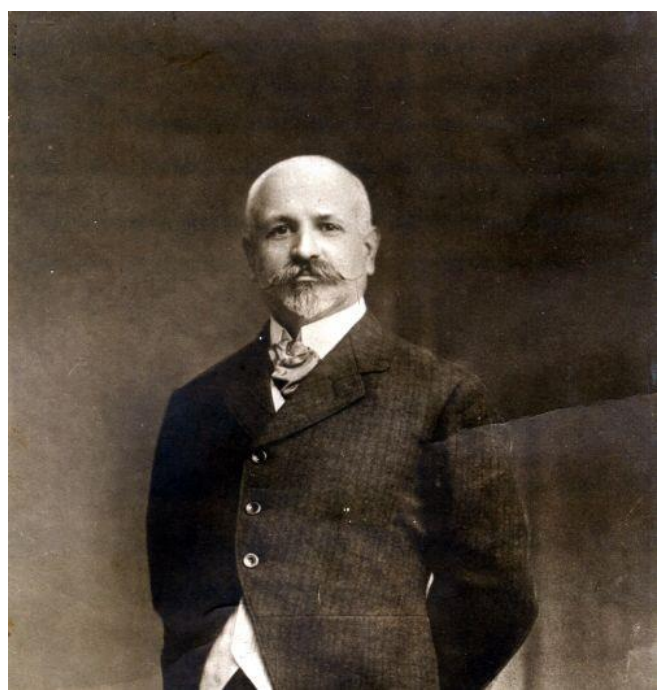

Fuente:<https://es.wikipedia.org/wiki/Semana_Tr\%C3\%A1gica_(Espa\%C3\%B1a)\#/media/File:Francisco_Fe rrer_Guardia.jpg>. 
En 1892 Francisco Ferrer inició su incursión en el anarquismo, participando en actividades organizadas por la Federación Internacional de Librepensadores.

En 1899 recorrió Europa y comenzó a elaborar sus conceptos educativos anarquistas. Fue cuando conoció a un grupo de anarquistas y anarcosindicalistas (Anselmo Lorenzo, Jean Grave, Jean Jaurés, Federico Urales) que influyeron decisivamente en su pensamiento.

El fallecimiento repentino de una exalumna suya que le dejó en herencia 1.300.000 francos para que pusiera en práctica su proyecto educativo y el apoyo de muchos compañeros, indujeron a Francisco Ferrer a regresar a Barcelona, con el objetivo de llevar a cabo el proyecto que había teorizado en los años anteriores.

En Barcelona Ferrer inauguró la Escuela Moderna (agosto de 1901), con el propósito de sustituir el estudio dogmático, por la razón y las ciencias naturales. También destacó su trabajo editorial, fundando la revista anarquista La Huelga General, con publicación quincenal entre 1901 y 1903 (SOLÀ i GUSSINYER, 1994).

Sin embargo, en 1905, cuando su método (pedagogía libertaria) provocaba la enemistad de los sectores conservadores y de la iglesia católica, su trabajo se vio interrumpido. La principal razón fue el hecho de que Mateo Morral, traductor y bibliotecario de su centro educativo perpetrase un atentado frustrado contra Alfonso XIII, implicando a Ferrer Guardia, por lo que estuvo encarcelado varios meses y cerradas sus escuelas.

Liberado, gracias a las campañas internacionales a su favor, quiso reabrir sus escuelas sin éxito, por lo que se trasladó a Bélgica y Francia, para dedicarse a la edición de textos escolares y ampliar internacionalmente su cuadro de colaboradores. En Bélgica fundó la Liga Internacional para la Educación Racional de la Infancia y en París dio continuidad a las ediciones del Boletín de la Escuela Moderna.

En julio de 1909, Ferrer volvió a Barcelona para visitar a su cuñada y a su sobrina que estaban enfermas, y también para tratar de asuntos referentes a la organización y edición de las obras El Hombre y la Tierra (Elisée Reclus) y La Grande Revolución (Piotr Kropotkin), y de la publicación de una enciclopedia de cultura popular de 15 volúmenes (SOLÀ i GUSSINYER, 1994, p. 85).

En esta ocasión Francisco Ferrer fue acusado de instigar los disturbios que caracterizaron la Semana Trágica de Barcelona (del 25 de julio al 6 de agosto de 1909), marcada por una huelga contra la decisión gubernamental de reclutar, entre los trabajadores, soldados para la guerra con Marruecos. El juicio que le condenó a la muerte estuvo envuelto en una serie de irregularidades y arbitrariedades. Le fusilaron el 13 de octubre de 1909.

La reacción al proceso contra Ferrer Guardia provocó una gran agitación en el mundo intelectual internacional. En esta ocasión se podían leer en periódicos, como The Times, frases en las que se criticaba la negligencia del gobierno español de la época al confundir la libertad de instrucción con la agitación criminal. Se publicaron cartas de intelectuales que destacaban que el crimen de Francisco Ferrer había sido el de ser republicano, libre pensador y haber creado la enseñanza laica que instruyó a miles de niños propiciándoles una moral independiente (ARCHER, 1911).

\section{La Escuela Moderna de Ferrer Guardia. Método y praxis}

"Lo repito; el niño no es de nadie; el niño se pertenece a sí mismo y, como toda falsa comprensión, lo que le despoja de sus derechos, lo que se esfuerza en modelarle sobre un tipo convencional saltando sobre predisposiciones y aptitudes naturales, conduce al desorden, al caos, al sufrimiento." (Boletín de la Escuela Moderna, Año III, nº 2, 1903, p. 70. In PUJOL-BUESQUETS, 1994). 
La escuela Moderna surge como oposición a la educación española oficial de finales del XIX basada en el control eclesiástico sobre la educación. Fundada por Ferrer Guardia, y promovida por sectores republicanos radicales y por la clase trabajadora anarquista, su filosofía educacional (laicismo y positivismo) ha tenido, en el último siglo, una gran repercusión en todo el mundo occidental.

Sus bases doctrinarias eran el racionalismo librepensador surgido en el siglo XIX y el cientificismo positivista, y contenían una fuerte carga anticlerical, anticapitalista y antimilitarista. Su método educativo tenía como objetivo poner en práctica una educación volcada a la emancipación humana y a la edificación de una sociedad igualitaria.

Francisco Ferrer y sus seguidores consideraban que la verdadera educación racional no se basa en una razón artificial, sino en una razón natural, en el sentido de buscar la reconciliación del hombre consigo mismo, con su obra y con la naturaleza. Esta razón se rige por las leyes de solidaridad entre sus elementos (apoyo mutuo kropotkiniano).

La principal obra de Francisco Ferrer Guardia y la que contempla los fundamentos y principios de la escuela racionalista se domina "La Escuela Moderna" (figura 2) y es a partir de la misma y del "Boletín de la Escuela Moderna" que analizaremos las características de este modelo educativo.

Figura 2. La Escuela Moderna

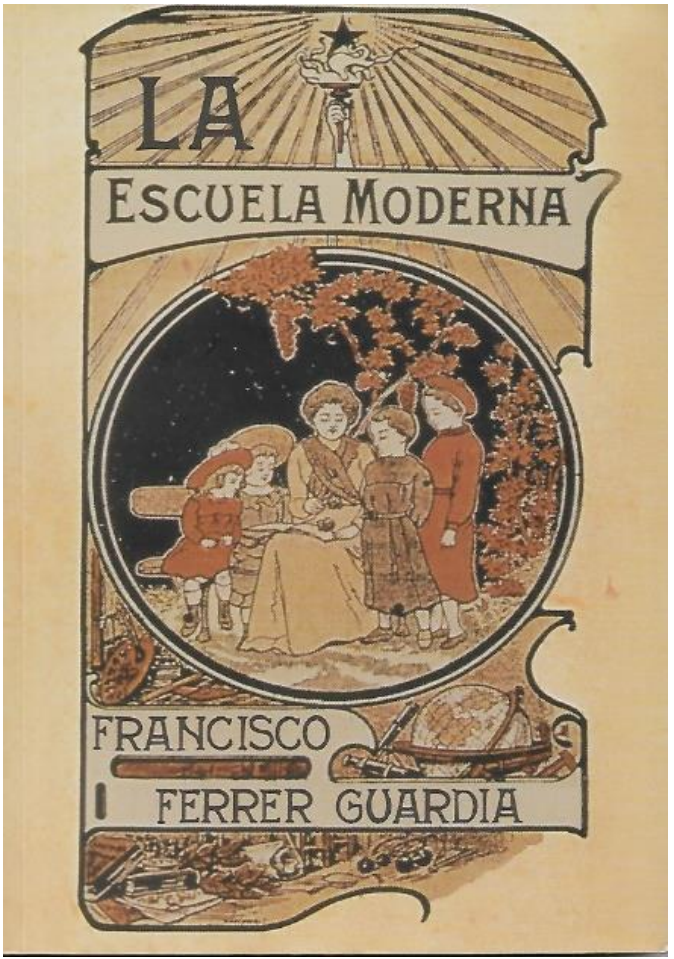

Fuente: foto de la autora

La Escuela Moderna se propuso desarrollar una educación desmistificadora y centrada en el niño. Se basaba en la crítica de la sociedad capitalista y en el papel de la escuela en la educación, ofreciendo una alternativa para estructurar una sociedad sin clases. Pretendía transformar la sociedad a partir de su base, la infancia, liberándola de sus privaciones pretéritas.

Su objetivo principal era combatir la desigualdad, ya que defendía que la verdad es de todos y socialmente se debe a todo el mundo. Según Ferrer Guardia, el propósito de la 
educación mixta (coeducación) es que ambos sexos tengan educación idéntica y que la mujer se transforme en la compañera del hombre. La mujer no debe estar recluida en su hogar. Además, la coeducación pone en contacto a niños pobres y ricos, lo que les infunde ideas de igualdad.

De esta misión, Francisco Ferrer Guardia excluía al Estado y otras instituciones oficiales porque creía que era donde se encontraban los tenedores de los privilegios y los mentores de las leyes que consagraban la explotación del hombre por el hombre. Consideraba que las escuelas que estaban al servicio del Estado y de sus gobernantes se transformaban en instrumentos de dominación.

Con la meta de implementar esta pedagogía, cuya orientación engendraría una sociedad justa, daba la siguiente recomendación a los profesores: Nunca se hará lo suficiente en favor de los niños. Los cuidados para con los niños deben ser guiados por el buen sentido, no basta tener buena voluntad, si necesita también conocimientos y experiencia (FERRER GUARDIA, 2009, p. 114).

Con respecto a la educación en la primera edad, reitera que el profesor debe plantar las semillas de las ideas. La misión de la enseñanza consiste en hacerlo a través de un método científico y empírico, por medio de experiencias o actividades vinculadas a lo cotidiano infantil o a lo de su comunidad, como se publica en el Boletín de la Escuela Moderna:

\begin{abstract}
"Su propósito es coadyuvar rectamente, sin complacencias con los procedimientos tradicionales, a la enseñanza pedagógica basada en las ciencias naturales. Este método nuevo, pero el únicamente real y positivo, ha cuajado por todos los ámbitos del mundo civilizado, y cuenta con innúmeros obreros, superiores de inteligencia y abnegados de voluntad." (Boletín de la escuela Moderna, (Boletín de la Escuela Moderna, Año I, nº 1, 1901 In FERRER GUARDIA, 2009, p. 85).
\end{abstract}

Esta "instrucción práctica" que también puede estar asociada a los trabajos manuales serviría de fundamento a la razón natural (FERRER GUARDIA, 2009, p. 204-5), que propiciaría al niño asimilar la instrucción abstracta, como la lectura, la escritura, los cálculos, los contenidos de geografía, historia, etc., que por sí solas no tendrían utilidad para él.

En los tres primeros años de funcionamiento, la Escuela Moderna de Barcelona obtuvo un incremento importante en su número de alumnos, llegando a tener, al final del año escolar de 1903-1904, 114 matriculados (tabla 1).

Tabla 1. Evolución del número de alumnos en las escuelas barcelonesas de Ferrer i Guardia entre 1901 y 1904

\begin{tabular}{|l|r|r|r|r|r|r|r|r|r|}
\hline & \multicolumn{4}{|c|}{$1901-1902$} & \multicolumn{3}{|c|}{$1902-1903$} & \multicolumn{3}{|c|}{$1903-1904$} \\
\hline \multicolumn{1}{|c|}{ MESES } & NIÑNA & NIÑS & TOTAL & NIÑS & NIÑS & TOTAL & NIÑAS & NIÑOS & TOTAL \\
\hline Septiembre & 16 & 23 & 39 & 23 & 40 & 63 & 24 & 40 & 64 \\
\hline Octubre & 18 & 25 & 43 & 28 & 40 & 68 & 43 & 59 & 102 \\
\hline Noviembre & 21 & 29 & 50 & 31 & 40 & 71 & 44 & 59 & 103 \\
\hline Diciembre & 22 & 30 & 52 & 31 & 40 & 71 & 45 & 59 & 104 \\
\hline Enero & 22 & 32 & 54 & 31 & 44 & 75 & 47 & 60 & 107 \\
\hline Febrero & 23 & 32 & 55 & 31 & 48 & 79 & 47 & 61 & 108 \\
\hline Marzo & 25 & 34 & 59 & 33 & 47 & 80 & 49 & 61 & 110 \\
\hline Abril & 26 & 37 & 63 & 32 & 48 & 80 & 50 & 61 & 111 \\
\hline Mayo & 30 & 38 & 68 & 33 & 48 & 81 & 51 & 62 & 113 \\
\hline Junio & 32 & 38 & 70 & 34 & 48 & 82 & 51 & 63 & 114 \\
\hline
\end{tabular}

Fuente: Elaborado por la autora a partir de Ferrer Guardia, 2009, p. 176. 
En el año 1905 había, en esta misma ciudad una decena de escuelas que adoptaron sus métodos y principios, y en la provincia de Barcelona, alcanzaban la cifra de 147 unidades. En total estas escuelas podrían albergar, según Ángel Cappelletti, aproximadamente mil alumnos.

\section{La Escuela Moderna: metodología y praxis}

Defendiendo la praxis frente al conocimiento abstracto, Ferrer Guardia subraya que se debe comenzar por la enseñanza del trabajo manual (instrucción práctica), porque la instrucción (aprender a leer, escribir, calcular, estudiar geografía o historia) por sí, no tiene utilidad para el niño. Se trata de fundar la razón natural (FERRER GUARDIA, 2009, p. 204$5)$.

Ferrer evoca que "todo el valor de la educación reside en el respeto a la voluntad física, intelectual y moral del niño" (2009, p.124), y que ella debe estar exenta de cualquier dogmatismo. Además, "el verdadero educador es aquel que, contra sus propias ideas y sus voluntades, puede defender al niño, apelando en mayor grado a las energías propias del niño" (FERRER GUARDIA, 2009, p.124). Su raciocinio lo estimula a instituir algunos parámetros con vistas a la renovación de la escuela, y establece los juegos como un ejercicio pedagógico.

\section{Los juegos como mejor método de aprendizaje}

Ferrer Guardia resalta que el juego es imprescindible para los niños porque en ellos manifiestan sus deseos y sus alegrías, una situación impensable en la educación religiosa, que entiende que "la vida es una cruz". La Escuela Moderna difunde que la vida es para disfrutarla, para vivirla (COLUMBIÉ, in FERRER GUARDIA, 2009, p.109).

El juego es apto para desarrollar en los niños el sentido altruista, es donde se debe orientarle para que practique la solidaridad. Los juegos también sirven para conocer la personalidad del niño. El niño juega a ser adulto y cuando llega a la fase adulta hace en serio lo que de niño le divertía (COLUMBIÉ in FERRER GUARDIA, 2009, p. 110-111).

Por esto, en la Escuela Moderna, consideran que, para los más jóvenes, el mejor método de aprendizaje son los juegos y las actividades manuales, y los estudiantes mayores aprenden a poner en común sus respectivos puntos de vista y sus experiencias personales.

Según Ferrer Guardia, la introducción de las ciencias experimentales y los conocimientos que éstas producen harían que el niño abandonara poco a poco el juego, un juego que no es en sí más que una forma de trabajo, debido a su gusto atávico por la lucha, subsistente desde los primordios de la vida. Cuando esto ocurre, se interpone la influencia del educador (oculta e indirecta). Su conocimiento de la vida le ayudará a comprender lo que le pasa al alumno y le ofrecerá lo que le pida (FERRER GUARDIA, 2009, p. 205-206).

A medida que avance en su aprendizaje, el alumno presentará la necesidad de saber, de instruirse, y en este momento se le debe cuidar para que no se ahogue en esta necesidad, facilitándole los medios para que pueda satisfacerla. De este modo, saldrán de nuestras escuelas hombres y mujeres dispuestos a cultivar todas las ramas del saber y de la actividad, guiados por la razón e inspirados por la ciencia y el arte, que embellecerán la vida y justificarán la sociedad (FERRER GUARDIA, 2009, p. 205-6 y 140).

\section{"Ni premio ni castigo"}

Ferrer Guardia condena los exámenes y los premios cuyas solemnidades satisfacen el amor propio de los padres y los intereses de muchos profesores a expensas de las torturas 
de los niños en las pruebas y exámenes. Y justifica: "en el colegio todo tiene que ser efectuado en beneficio del estudiante. Todo acto que no consiga ese fin, debe ser rechazado como antitético a la naturaleza de una positiva enseñanza" (BOIVIN in FERRER GUARDIA, 2009, p. 131).

La Escuela Moderna debe difundir la solidaridad y la igualdad, por lo tanto, no debe haber premios, ni castigos ni tampoco exámenes. Esto eliminaría la angustia de los estudiantes, la vanidad de los premiados y la humillación de los demás. La competición genera enemistad y envidia, afirma Ferrer Guardia.

Estas prácticas irracionales y atávicas deben desaparecer de la pedagogía moderna. Se debe renunciar, también, a cualquier castigo material o moral. Según Ferrer, en las escuelas libres todo deberá ser paz, alegría y confraternización.

Los pedagogos deben evitar mostrar a los estudiantes la noción de comparación, pero facilitar la comprensión y apreciación de la diversidad infinita (BOIVIN in FERRER GUARDIA, 2009, p. 134).

Con respecto a los padres, resalta que deben, hasta cierto punto, mantenerse pasivos en la obra educadora. El adulto, según Ferrer, no debe imponer al niño su punto de vista ni tampoco sus valores.

\section{La enseñanza de la geografía y las excursiones}

Para Ferrer Guardia, toda enseñanza de la ciencia moderna debe ser una "vuelta a la naturaleza". Por este motivo, antes de hablar de "geografía" o utilizar libros y mapas los profesores deberían llevar a sus alumnos para hacer largos paseos e incluso viajes, organizados a partir del método racionalista. La observación directa de la Tierra debe adaptarse a la realidad física y social de cada lugar.

Ferrer reproduce un texto de Élisée Reclus en el que rechaza los mapas planos por sus errores y propone como punto de partida para enseñar geografía un globo (una bola colgada) en la que el profesor pueda dibujar el Ecuador y el meridiano de Greenwich, y una elíptica que le permita enseñar las estaciones del año, situar el punto donde está la escuela y otras regiones de la Tierra o explicar las teorías sobre la redondez planetaria. Posteriormente, los alumnos dibujarán en éste y otros mapas los continentes, mares y todo lo que aprendieron. El verdadero método consiste en ver, crear de nuevo y no sólo repetir mnemónicamente (FERRER GUARDIA, 2009, p. 146-150).

Ferrer Guardia también defendió las excursiones escolares en las adyacencias de las escuelas, en los pueblos más cercanos, sea acompañando el curso de un río y analizando su morfología y sus márgenes, o visitando propiedades rurales, donde pueden contactar con agricultores y otros trabajadores. Afirmó: la pedagogía positiva, a la que se propone enseñar verdades, debe metodizar y sistematizar los conocimientos positivos de la naturaleza, inculcarlos en la infancia y preparar así elementos para una sociedad equitativa (FERRER GUARDIA, 2009, p. 174).

\section{El libro didáctico}

La Escuela Moderna considera el libro de texto solo como un punto de apoyo para profesores y alumnos, ya que este estimula al educando para que reconstruya activamente los procesos elementales del saber, la observación, la investigación y espíritu crítico. También defiende la libre actividad cooperadora del educando, que muchas veces se constituye en educador de sus compañeros más jóvenes. 
En 1904 había un gran número de escuelas que utilizaban los libros elaborados por la Escuela Moderna.

Respecto a la enseñanza de geografía en las escuelas primarias, Ferrer sigue el concepto reclusiano (E. Reclus), sosteniendo la no utilización de libros de texto, sin embargo, cree posible la utilización de un manual que sirva de guía. Opina que la enseñanza oral es la mejor, después viene la redacción de notas y la elaboración de mapas (FERRER GUARDIA, 2009, p. 151-2).

\section{La aritmética}

La Escuela Moderna defiende el planteamiento de los problemas fáciles y prácticos que no traten de dinero, ahorro o lucro. En su lugar los ejercicios deben versar sobre temas vinculados a la ciencia de la economía social: la producción, el transporte y la distribución de materias primas y de víveres, la comunicación, el trabajo humano comparado con el mecánico, etc.

Partiendo de esas consideraciones y aplicándolas a la pedagogía, Ferrer también juzga necesario que los niños comprendan que derrochar toda clase de materiales y objetos es contrario al bienestar general (FERRER GUARDIA, 2009, p.198).

Sobre los resultados de este nuevo modelo de escuela, racionalista y laica, Ferrer Guardia afirmó: "La ciencia [en un sentido amplio] es la exclusiva maestra de la vida". La Escuela Moderna se propone dar a los niños vitalidad cerebral propia, para que razonen sus propias convicciones (FERRER GUARDIA, 2009, p.160).

\section{La Universidad Popular}

La metodología utilizada en la Escuela Moderna incluía conferencias dominicales a las que acudían alumnos, sus familias y un gran número de trabajadores. Entendiendo que todo ser humano tiene derecho a saber y que la ciencia no debe estar vinculada solamente a los investigadores, Ferrer Guardia firmó un convenio con profesores catedráticos de la UB (Andrés Martínez Vargas y Odón del Buen) para que pronunciasen, en las universidades populares, conferencias que sucederían con regularidad y versaban sobre temas que estaban vinculados a las especialidades de los conferenciantes: Geografía e Historia Natural, Fisiología e Higiene Escolar, etc. El anuncio de las mismas se hacía a través de los periódicos liberales locales (FERRER GUARDIA, 2009, p. 155-156).

\section{Boletín de la Escuela Moderna}

La publicación del Boletín de la Escuela Moderna tuvo inicio en octubre de 1901. Con una periodicidad mensual, poseía un interés esencialmente educativo, dirigido a la enseñanza racional y científica. Tenía como objetivo divulgar el funcionamiento y las actividades de la escuela, así como libros y artículos publicados por pedagogos, geógrafos, literatos, filósofos, médicos, etc., vinculados al pensamiento moderno, de cuño racionalista.

La vigencia de este Boletín fue de casi ocho años, entre octubre de 1901 y 1 de julio de 1909, y se organizó por años escolares: año I (1901-1902, 100 páginas), año II (19021903, 96 páginas), año III (1903-1904, 108 páginas), año IV (1904-1905, 120 páginas), año V (1905-1906, 112 páginas), no se publicó el último número debido a la paralización judicial de la editorial. Debido al encarcelamiento de Ferrer y el cierre de sus escuelas, el Boletín VI (1906-1907) constó de un solo ejemplar correspondiente al período entre junio de 1906 y julio de 1907, siguiendo la numeración correspondiente al año escolar anterior (páginas 113124). Su publicación fue retomada entre mayo de 1908 y julio de 1909. 
En esta nueva fase, la portada del Boletín incluía las expresiones "Enseñanza Científica y Enseñanza racional" (figura 3) (PASCUAL VELAZQUEZ, 2008).

\section{Figura 3. Boletim da Escola Moderna de 1908}

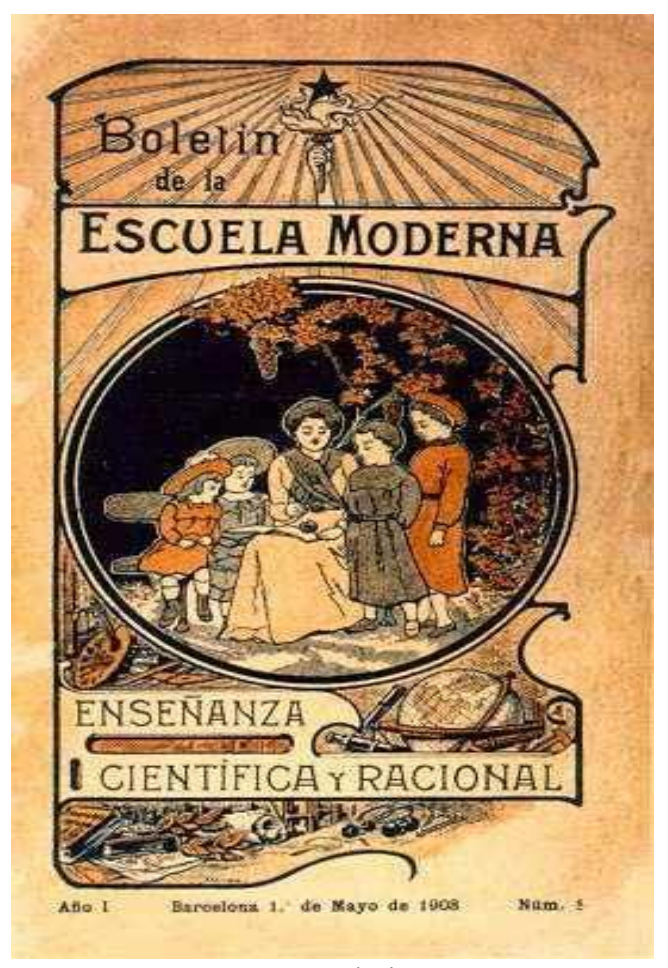

Fuente: Foto de la autora

En mayo de 1908 en el Boletín destacó la publicación de las bases y del estatuto de la Liga Internacional para la Educación Racional de la Infancia, que tenía sede en París (FUNDAÇÃO FERRER I GUARDIA).

La condena de Ferrer Guardia fue el motivo por el cual el Boletín de la Escuela Moderna no tuvo continuidad después de julio de 1909.

Las actividades de la editora Escuela Moderna prosiguieron tras la muerte de Ferrer Guardia, puesto que, antes de ser fusilado, la dejó, en testamento a Lorenzo Portet. En el mismo testamento, además de recomendar la edición de varias obras, Ferrer aconsejó a Lorenzo viajar por Europa a la búsqueda de buenos libros y le sugirió la publicación de una revista o diario semanal que abordara como temática la educación racionalista y también el sindicalismo.

Sin embargo, la editorial sólo volvió a sus actividades en 1912, cuando la confiscación de los bienes de Ferrer fue anulada. Entre las muchas obras publicadas por la editorial están Ferrer. Páginas para la Historia (1912) y en 1915 una compilación de los Boletines de la Escuela Moderna publicados entre 1901 y 1909. Sus actividades finalizaron en 1920 (PASCUAL VELÁZQUEZ, 2008).

\section{Reflexión final}

Las bases doctrinales de la escuela de Ferrer Guardia fueron tres: a) el racionalismo librepensador del siglo XIX que dio origen a confederaciones de escuelas laicas; b) el 
cientificismo positivista evolucionista; y, c) la crítica social libertaria del papel de la escuela y de la educación (SOLÁ GUSSINYER, 2009, p. 29).

La filosofía educativa defendida por Ferrer Guardia no trataba simplemente de criticar la trayectoria de la escuela tradicional, sino sobre todo de una alternativa sociopolítica y moral, basada en la ciencia y la razón, descartando totalmente todo tipo de enseñanza religiosa. Propuso el desarrollo armónico de los conocimientos intelectuales, morales, profesionales y las aptitudes físicas (JORGE PUJOL-BUSQUETS, 1994, p 72).

Según Francisco Ferrer Guardia "La moderna pedagogía, despojada de tradiciones y convencionalismos, ha de ponerse a la altura del concepto racional del hombre, de los actuales conocimientos científicos y del consiguiente ideal humano.” (2009, p. 170).

Estas afirmaciones refuerzan la idea de que la Escuela Moderna de Francisco Ferrer Guardia, poseía un estrecho vínculo con el movimiento racionalista educativo en función de sus ideas comunes: los problemas políticos y sociales son esencialmente pedagógicos y la educación es el motor de cambio social.

Sus teorías pedagógicas y sus prácticas, cuyas bases nos remiten a los ideales de la Ilustración y de la corriente ácrata (libertaria), han perdurado en el tiempo y se han difundido espacialmente. Durante el siglo XX fueron un modelo a seguir en diferentes países y regiones, en los que, con el objetivo de conseguir un nuevo 'orden social', se buscó implantar iniciativas asociadas a una educación libertaria, como única vía para la conquista de la autonomía y libertad de los individuos a través del desarrollo de todas sus potencialidades. Condiciones esenciales para que se produjera un auténtico desarrollo social, en el que la razón y la igualdad de oportunidades serían las protagonistas.

\section{Bibliografía}

ARCHER, William. The life, trial and death of Francisco Ferrer. Nova York: Moffat, Yard and Compan, 1911

<https://archive.org/stream/lifetrialdeathof00archuoft\#page/n295/mode/2up>.

BAKUNIN, Mijaíl. La instrucción integral. Ginebra, L'Egalité, 31 de julio de 1869 $<$ https://www.portaloaca.com/pensamiento-libertario/textos-sobre-anarquismo/5807-lainstruccion-integral-mijail-bakunin.html>.

BAKUNIN, Mijaíl. Escritos de Filosofía Política I. Biblioteca anarquista, 1953 $<$ https://es.theanarchistlibrary.org/library/mijail-bakunin-escritos-de-filosofiapolitica.pdf $>$.

BAKUNIN, Mijaíl. Dios y el Estado. Proyecto Espartaco 2000-2001 $<$ https://mx.123dok.com/document/rz3lpeez-mijail-bakunin-proyecto-espartaco-20002001.html>.

BOIVIN Emilia. Ni premio ni castigo. In FERRER i GUARDIA, Francisco. La Escuela Moderna. Póstuma explicación y alcance de la enseñanza racionalista. Barcelona: Tusquets Editores, 2009 [1976], p. 128-135.

CAPPELLETTI, Angel. La Escuela Moderna en America Latina. Educació i història. $\begin{array}{llllll}\text { Revista d'història de l'educació, 1994, } \mathrm{n}^{\mathrm{o}} & 1, & \text { p. } & \text { 29-31 }\end{array}$ <http://revistes.iec.cat/index.php/EduH/article/view/535/51298>. 
COLUMBIÉ, R. Los juegos. In FERRER i GUARDIA, Francisco. La Escuela Moderna. Póstuma explicación y alcance de la enseñanza racionalista. Barcelona: Tusquets Editores, 2009 [1976], p. 107-111.

FERRER i GUARDIA, Francisco. La Escuela Moderna. Póstuma explicación y alcance de la enseñanza racionalista. Barcelona: Tusquets Editores, 2009 [1976].

FUNDACIÓN FERRER I GUARDIA <http://www.ferrerguardia.org/es/>.

INSTITUCIÓN LIBRE DE <https://es.wikipedia.org/wiki/Instituci\%C3\%B3n_Libre_de_Ense\%C3\%B1anza>

KROPOTKIN, Piotr. La conquista del pan. Madrid: Zero S. A., 1973. Título original: La Conquête du Pain, Paris, Tresse et Stock, 1892, com prefácio de Élisée Reclus.

KROPOTKIN, Piotr. Campos, fábricas y talleres. Madrid: Zero, 1978. Título original: Champs, Usines et Ateliers, ou l'industrie combinée avec l'agriculture et le travail cérébral avec le travail manuel, Paris, P. V. Stock Éditeur, 1910.

LIDA, Clara. Educación anarquista em la España del ochocientos. Revista de Occidente, 1971, nº 97, p. 33-47 <https://dialnet.unirioja.es/servlet/articulo?codigo=4863324>.

MONES i PUJOL-BUESQUETS, Jordi. Francesc Ferrer i Guardia i l'Escola Nova. Educació i història. Revista d'història de l'educació, 1994, $\mathrm{n}^{\mathbf{0}}$ 1, p. 69-72 $<$ https://dialnet.unirioja.es/servlet/articulo?codigo=3794258>.

PESTALOZZI, Johan Heinrich. Cartas sobre Educación Infantil $<$ https://iessecundaria.files.wordpress.com/2013/02/pestalozzi-johann-cartas-sobreeducacion-infantil1.pdf $>$.

PROUDHON, Pierre-Joseph. O que é a propriedade? Lisboa: editorial Estampa, 1975, $2^{\mathrm{a}}$ ed. Tradução de Marília Caeiro.

RECLUS, Élisée. O Homem é a natureza adquirindo consciência de si própria. In: ANDRADE, Manuel Correia (Org); FERNANDES, Florestan (Coord). Élisée Reclus. São Paulo: Editora Ática, 1985. p. 38-40. Título original: Préface. L'homme est la nature prenant conscience d'elle-mêsme. L'homme et la Terre, tomo I.

RECLUS, Élisée. A evolução, a revolução e o ideal anarquista. São Paulo: Editora Imaginário/Expressão \& Arte Editora, 2002. Título original: La évolution, la révolution et l'idéal anarchique.

ROBIN, Paul. Manifiesto a los partidos de la educación integral. Barcelona: Siglo XXI de Catalunya, 1981. Publicación original: L'educatione intégrale, 1901, $\mathrm{n}^{\circ} 1$ $<$ http://colectivoescuelaabierta.org/wpcontent/uploads/2016/06/Manifiesto_Educacio\%CC\%81n_Integral.pdf>. 
ROSELL, Albano. El poder de la educación. Ensayo de Le Combat Syndicaliste, París. texto escrito em Montevideu, julho de 1940

<https://anarkobiblioteka3.files.wordpress.com/2016/08/el_poder_de_la_educacic3b3n__albano_rosell.pdf>.

ROUSSEAU, Jean-Jacques. EI Contrato Social o Principios de derecho político. Madrid: EDAF Ediciones, 1998.

ROUSSEAU, Jean- Jacques. Emilio. Barcelona: RBA Coleccionables, 2002.

SAFÓN, Ramón. Las fuentes pedagógicas de la Escuela Moderna. Educació i història. Revista d'història de l'educació, 1994, $\mathrm{n}^{\mathrm{o}} \quad 1, \quad$ p. $73-75$. <https://dialnet.unirioja.es/ejemplar/292571>.

SOËTARD, Michel. Johan Heinrich Pestalozzi (1746-1827). Paris, Unesco, 1999 <http://www.ibe.unesco.org/sites/default/files/pestalozzis.PDF>.

SOLÀ GUSSINYER, Pere. Escritos de Francesc Ferrer i Guardia. Educació i història. Revista d'història de l'educació, 1994, $\mathrm{n}^{\circ} \quad 1, \quad$ p. 83-94. <https://dialnet.unirioja.es/ejemplar/292571>.

SOLÀ GUSSINYER, Pere. Prólogo a la edición de 2009 de La Escuela Moderna. In FERRER GUARDIA, Francisco. La Escuela Moderna. Póstuma explicación y alcance de la enseñanza racionalista. Barcelona: Tusquets Editores, 2009 [1976].

VELAZQUEZ VICENTE, Pascual. La Escuela Moderna. Una editorial y sus libros de texto (1901-1920). Universidade de Murcia: Tese doutoral, 2008 $<$ https://pascualvelazquez.com/wp-content/uploads/2017/04/Tesis-Doctoral-EscuelaModerna.-Pascual-Vel\%C3\%A1zquez.-Volumen-I.pdf $>$.

ZAAR, Miriam Hermi. Élisée Reclus e o seu método geográfico. Biblio 3W. Revista Bibliográfica de Geografía y Ciencias Sociales. [En línea]. Barcelona: Universidad de Barcelona, 15 de junio de 2015, Vol. XX, no 1.123 <http://www.ub.es/geocrit/b3w1123.pdf>.

ZAAR, Miriam Hermi. As concepções ácratas de Élisée Reclus e Piotr Kropotkin e suas influências em projetos urbanos e experiências impulsadas por movimentos sociais dos séculos XX e XXI. In Actas del XIV Coloquio Internacional Geocrítica, Las utopías y la construcción de la ciudad del futuro. Barcelona: Universidad de Barcelona, 2016 <http://www.ub.edu/geocrit/xiv-coloquio/MiriamZaar.pdf>. 